\title{
OS VESTÍGIOS DE UMA ÉPOCA DE CASOS RAROS ${ }^{1}$
}

Vera Collaço (orientadora) e Ana Luiza da Luz (bolsista PIBIC)

\begin{abstract}
RESUMO: Na década de 1920 o teatro de revista popularizou-se na cidade de Florianópolis, fazendo com que os intelectuais catarinenses se interessassem pelo gênero e produzissem assim revistas sobre os costumes locais. Neste contexto, Nicolau Nagib Nahas, escreveu a sua revista intitulada $A$ ilha dos casos raros, fazendo um panorama da situação política e social de Florianópolis no ano de 1926. Assim a revista nos fornece um recorte verdadeiro dos costumes e acontecimentos da ilha dos casos raros.
\end{abstract}

PALAVRAS-CHAVE: Teatro de Revista, Florianópolis e Análise de texto

Neste artigo buscamos estabelecer as relações entre a conjunção política e social do Estado de Santa Catarina, no ano de 1926, com a revista catarinense A ilha dos Casos Raros, cujo autor é Nicolau Nagib Nahas. A revista foi apresentada no Teatro Álvaro de Carvalho no dia 29 de maio de 1927, referindo-se em especial aos acontecimentos do ano anterior, de 1926, como é próprio das revistas de ano. Para isso faremos uma breve análise da obra, verificando seus aspectos temáticos, para melhor entendê-la no panorama político e social dos anos 1920. Assim, procuramos verificar como esse gênero teatral, tão popular nas cidades do Rio de Janeiro e São Paulo, atuou e comentou o contexto da cidade de Florianópolis.

\section{A revista conta a história...}

Uma obra de arte fornece-nos vestígios do que foi uma época, como o homem se relacionava com seu tempo, como o encarava, o interpretava e o representava. Lançando um olhar histórico sobre um objeto artístico podemos notar os rastros

\footnotetext{
${ }^{1}$ Projeto de Pesquisa: A revista seduz a elite de Florianópolis. Centro de Artes. Orientação: Prof ${ }^{a}$. Dra. Vera Regina Martins Collaço. Departamento de Artes Cênicas. Bolsista: Ana Luíza da Luz (PIBIC).
} 
históricos que ele deixou, e a partir daí o encaramos como um documento que discute uma dada realidade. Porém, como alerta Maria Bernadete Ramos Flores,

Não se trata de entender a obra como reflexo do contexto e muito menos de considerar a história como pano de fundo [...] Trata-se de entender a produção artística como parte constituinte do discurso histórico, do qual a obra-de-arte tem lugar não apenas pelas imagens intercaladas, ou como simples procedimentos retóricos, mas como acontecimento histórico ${ }^{2}$.

Por termos como objeto de estudo uma Revista os aspectos históricos ganham uma dimensão maior, naturalmente. Tendo em vista as características básicas de uma peça do gênero revista, cujo aspecto do retrato da realidade é o objetivo primeiro, tornase então um rico documento histórico, por sua própria estrutura e convenções. As revistas de ano, gênero que $A$ ilha dos Casos Raros se enquadra, buscam passar em revista os fatos reais ocorridos na cidade no ano anterior, fatos estes sempre reais, para que o público os reconheça e possa lançar um olhar crítico, através de sátiras e paródias. A revista esta intimamente ligada com a atualidade, comprometendo-se a comentá-la, numa espécie de retrospectiva do ano anterior. Por esse seu aspecto atual, torna-se um pertinente documento de pesquisa, mas também muitas vezes complicado de decodificação nos anos posteriores, quando nos faltam dados sobre os fatos, as alegorias e as caricaturas, não podemos entendê-la em sua completude por falta de referenciais.

\section{Os republicanos estão no poder e nos palcos da Ilha}

Filho de imigrantes turcos, Nicolau Nagib Nahas nasceu no ano de 1898 na cidade de Campos no estado do Rio de Janeiro, mudando-se ainda criança para Florianópolis, onde estabeleceu seus vínculos pessoais e profissionais. Aos 35 anos de idade, no auge de sua carreira como escritor, Nahas é vitimado da tuberculose e morre no ano de 1934.

Em 1927, quando foi escrita a revista local A Ilha dos Casos Raros, seu autor, Nahas já era reconhecido na cidade por suas crônicas nos principais jornais de Florianópolis, bem como por suas poesias. No ano de 1922, Nahas é convidado pelo governo do Estado, representado pelo republicano Hercílio Luz, a publicar suas poesias

\footnotetext{
${ }^{2}$ FLORES, 2006, p.33.
} 
em um livro comemorativo do centenário da Independência do Brasil. Assim o poeta catarinense publica Canções Incultas $^{3}$, uma modesta obra que teve uma repercussão discreta pela crítica, que afirmou que Nahas era "mais um artista espontâneo que não se preocupa muito com a perfeição [...] dentro da sua espontaneidade produz obras belas e outras medíocres". ${ }^{4}$ Porém, mesmo assim, o livro de poesias popularizou ainda mais o jovem autor entre seus conterrâneos e certamente o incentivou nas suas aventuras literárias.

Nahas trabalhou como escrivão do cartório da cidade, foi capitão da guarda municipal e tenente da polícia militar, mas sua verdadeira vocação era a de escritor. Dedicava boa parte de seu tempo a escrever crônicas que enviava as redações dos principais jornais da capital, logo se tornando uma figura reconhecida e respeitada em toda cidade. Reconhecido não apenas pelos cidadãos e o meio intelectual da Ilha, mas também entre os políticos que se utilizaram da inteligência e capacidade de escrita de Nahas, servindo-se dele como orador nos comícios do Partido Republicano Catarinense (PRC), do Partido Liberal Catarinense (PLC) e eventos sociais dos grandes clubes de Florianópolis ${ }^{5}$. Porém, essa aliança de Nahas com o PRC é anterior a esta data, pelo menos desde 1922, como já foi citado, o poeta prestava seus serviços ao governador republicano Hercílio Luz, tendo sua obra apoiada por este. O envolvimento de Nahas com a política foi grande, era militante das idéias republicanas; em 1928 é um dos fundadores do Partido Liberal em Santa Catarina, fruto de uma cisão entre os republicanos descontentes, aumentando ainda mais seu envolvimento político. Em 1929 retorna ao PRC para participar ativamente da campanha a favor de Júlio Prestes a presidência da República, como orador dos comícios realizados no estado.

Nas primeiras páginas do livro Canções Incultas Nahas dedica a obra ao governo do Estado e, numa espécie de "retribuição" ao governador, lhe oferece uma poesia intitulada Dr. Hercílio Luz, onde de forma patriótica o exalta, deixando claro sua posição política e simpática pelo então governador, como podemos verificar nos seguintes versos ${ }^{6}$ :

\footnotetext{
${ }^{3} \mathrm{O}$ autor já havia publicado um pequeno livro de poesias intitulado Prelúdios Vespertinos em 1916 e em 1933 publica Boas Festas.

${ }^{4}$ ZICARELLI, 1925. (recorte de jornal colado no caderno de Nahas, com a inscrição "Publicado no jornal O Estado do Paraná, de 13 de janeiro de 1925") - material cedido para pesquisa por seu filho Gilberto Nahas.

${ }^{5}$ NAHAS, s/d - material cedido para pesquisa por seu filho Gilberto Nahas.
} 
Luctador incansável!

Coração que traduz sublimidade;

Alma justa e amorável

Onde se aninham o amor e a caridade!

[...]

Teu passado é um exemplo e o teu

futuro,

O' velho luctador republicano,

Far-te-há tão grande como Floriano!

A alma do Povo, em doce idolatria,

Sempre vibrando de enthusiasmo e ardor, Cheia de orgulho e cheia de ufania,

Ao teu nome de grande emprehendedor

Hã-de sempre clamar

E respeitar!

$[\ldots]^{7}$

Conforme podemos verificar Nahas não homenageia simplesmente o governador em pessoa, como faz propaganda de suas obras e deixa claro seu posicionamento, comparando o governador com o ex-presidente republicano Floriano Peixoto. Este mesmo sendo uma figura polêmica na cidade devido à chacina no Forte de Anhatomirim, havia quem o considera-se um mártir, o responsável pela consolidação do regime republicano no Brasil, independente dos meios que se utilizou para isso. Sendo durante o primeiro governo de Hercílio Luz, em 1894, que a cidade passa a se chamar Florianópolis, em homenagem a Floriano Peixoto.

O posicionamento político de Nahas, e a admiração por Hercílio Luz se repetem na revista A Ilha dos Casos Raros, onde sob o pretexto da visita de um forasteiro à Florianópolis, toda cidade é passada no palco, dando destaque as obras do governo de Hercílio Luz, que havia morrido dois anos antes, no ano de 1924. Esta revista mostra as mazelas da cidade de forma bastante crítica, sem poupar ironias e sátiras. Embora com um posicionamento ideológico claro, não perde o caráter denunciativo do gênero revista, sem ser uma propaganda política, ela se mostra como uma fotografia, sob a ótica do autor, sobre a atualidade da cidade, mostrando inclusive as mazelas do próprio PRC.

\footnotetext{
${ }^{6}$ Observo que quando fazemos citações dos jornais ou do material de Nahas preservamos nesta transcrição a escrita da época, por desejarmos provocar no leitor uma sensação de estranhamento ao entrar em contato com uma escrita bastante diferenciada da atual.

${ }^{7}$ NAHAS, 1922, p. 9.
} 


\section{Os casos raros de uma cidade que queria ser grande}

Durante toda a década de 1920, a cidade almejou a modernidade, promovendo várias reformas urbanas dentro dos novos padrões, preocupando-se com a higienização e arborização, numa busca de mudança de imagem da cidade, que antes era vista pelos viajantes que aqui passavam como velha, mal cuidada e suja. Dentro desse clima de euforia modernista, várias obras foram realizadas, desde construções de avenidas, como a Hercílio Luz, que na época era o Riacho da Fonte da Bulha, que desde aquela época apresentava graves problemas de higiene, sendo o local onde o esgoto domiciliar era destinado, sem tratamento. As ruas foram alargadas, o processo de aterramento da ilha teve início e a obra tão sonhada pelo povo florianopolitano foi realizada: a Ponte Hercílio Luz. É nesse clima de mudanças que a cidade começa a se relacionar com o restante do país, deixando de ser isolada para fazer parte do contexto sócio-político, tornando mais fácil o acesso à capital catarinense.

A cidade nos parece bailar, e, na vertigem própria dos dançarinos, levanta-se a urbe vertical, que se contorce e avança sobre o mar com seus aterros; suas veias se dilatam para dar passagem aos automóveis; sobejam artifícios a vesti-la de cores e formas para embelezá-la e receber forasteiros, viajantes, visitantes, turistas ${ }^{8}$.

Nahas é um dos entusiastas da modernidade, vê no governador Hercílio Luz o grande responsável pela modernização da cidade, prestando a ele homenagens também na revista A Ilha dos Casos Raros, como o próprio nome diz, uma cidade cheia de acontecimentos inusitados e incomuns. E são esses acontecimentos que Nahas apresenta na revista, ironizando e criticando a própria modernidade da capital, ou melhor, a tentativa frustrada em algumas obras mal feitas, bem como as personalidades que aqui habitavam, e que buscavam adotar novos padrões de comportamento, influenciados pela "moderna" São Paulo e Rio de Janeiro, que na verdade a maioria só conhecia pelos viajantes que aqui passavam. Desta forma, o autor na sua revista faz uma defesa à modernidade da cidade, porém crítica o mal cuidado das autoridades com as principais

${ }^{8}$ FLORES, 2006, p.11. 
ruas e praças, bem como com a lentidão de obras importantes, tais como o aterro das baias sul e norte. Ergue então, a bandeira da modernidade na cidade, consagrando os responsáveis, sem deixar de lado certa ambigüidade de posicionamento, característica das revistas.

No ano de 1926, retratado na revista, a Ponte Hercílio Luz foi inaugurada, portanto não contando com a presença de seu idealizador, que morrerá dois anos antes. A inauguração da primeira ponte que ligou a Ilha ao Continente é o principal acontecimento retratado na revista, pois ela "foi o elemento que identificou de forma contundente a primeira modernidade em Florianópolis, dividindo um tempo de atraso e um outro que supostamente se anunciava como portador do progresso" ". Dessa forma, Nahas não poderia deixar de dedicar um generoso espaço em sua revista para esse acontecimento. Apresenta a obra como o grande monumento da cidade e a principal realização de Hercílio Luz. Na cena em que o forasteiro é apresentado à alegoria da Ponte Hercílio Luz, a alegoria da Ilha faz o seguinte discurso:

Para iniciar iremos à Ponte, a essa obra monumental, que Hercílio Luz - Estadista que soube honrar o seu céspede natal e que foi uma glória na política nacional, fez construir, fazendo realidade um sonho secular que o meu povo julgava irrealizável! ${ }^{10}$

Mesmo nesse momento de homenagem, Nahas não deixa de alfinetar e comentar a corrupção, e em um discurso cheio de comoção, que encaminha à apoteose do primeiro ato, que homenageia o ex-governador, temos a seguinte fala:

Ilha: Pena é que fosses explorada por uma sociedade anonyma, que comeu parte dos teus lucros e dos teus proventos.

$$
[\ldots]
$$

PONTE: E sabem por que aqui me encontro? Sou filha e do esforço da vontade daquelle homem (aponta par ao retrato do Dr. Hercílio Luz) Sim, sou filha daquelle homem que, se teve o ímpeto e a energia de um vendaval; se foi as vezes enérgico demais; foi também, calma e tranqüilidade como um dia claro de sol ardente, foi também manso como um cordeiro. É a elle que tu, a Ilha Encantada, deves o saneamento das tuas ruas, a belleza (sic) das tuas avenidas e a glória na política da tua gente moça a

${ }^{9}$ FLORES, 2006, p.24

${ }^{10}$ NAHAS, 1927, s/p. 
quem elle legou os mais nobres ensinamentos. E a morte! Como é injusta a morte! Não quis, que elle visse a sua immensurável obra depois de concluída e entregue ao transito do povo que o fizera de ídolo muito amado e querido.

A sociedade anônima a que a alegoria da Ilha se refere é um pequeno grupo de empresários e políticos que se beneficiaram com a cobrança de pedágio para que se transitasse entre a ilha e o continente. A alegoria responde afirmando que a Ponte só é uma realidade graças a Hercílio Luz, confirmando o carisma que o ex-governador tinha e justificando de forma leve e discreta suas truculências no poder e sagacidade para conquistar os mais pobres e calar seus oponentes políticos.

Ao referir-se a Avenida Hercílio Luz, Nahas volta a demonstrar seu desejo de modernidade, por meio da alegoria da própria avenida diz que "toda ella é arborizada com farta iluminação [...] quem dera bondes elétricos para me dar maior vida" "11. A avenida torna-se aqui porta voz de toda a cidade, que deseja deixar de depender de cavalos e charretes, tendo em vista os poucos carros que havia em Florianópolis, para assemelhar-se as grandes cidades do país. O pedido é endereçado ao novo governador do Estado Adolpho Konder, que assumiu o poder logo após a morte de Hercílio Luz.

Quanto ao governador Adolpho Konder a posição de Nahas está explicitada na fala da alegoria a Ilha:

O homem que dirige com braço forte os destinos do meu Estado e que uniu num belle gesto de paternidade os partidos e as classes e implantou o regime da paz e da concórdia nesta Ilha tão cheia de discórdia e de intrigas.

Aqui Nahas está se referindo as rivalidades e jogos de interesse dentro do PRC, que Adolpho Konder conduziu, num primeiro momento, à unificação e concordância. Porém, o governador não conseguiu segurar as pressões internas e a cisão ocorreu ainda no ano de 1927 quando foi criado o Partido Liberal Catarinense (PLC), liderado por Vidal Ramos, ao qual Nahas curiosamente fez parte e militou. O PLC foi fundado como oposição ao governo e a oligarquia republicana que vinha dominando o Estado há alguns anos. Porém, é importante frisar que a revista foi escrita e apresentada antes da fundação do PLC, portanto, Nahas ainda estava ao lado do PRC, ou nunca deixou de ${ }^{11}$ NAHAS, 1927, s/p. 
estar, tendo em vista que em 1929 pronunciou discursos em comícios a favor de Julio Preste, ao qual o PLC foi contrário.

Outro fato ocorrido neste ano de 1926 e que Nahas na Ilha dos casos raros fez questão de dar destaque, foram às nomeações pelo Presidente da República, Washington Luiz, de três catarinenses para ocupar o primeiro escalão do governo federal, sendo eles Victor Konder, Nestor Sezefredo do Passos e Arnaldo Siqueira Pinto da Luz. A indicação torna-se um grande acontecimento, "a inesperada notícia varre Santa Catarina em meados de outubro. E o orgulho dos catarinenses explode em alegres festas populares em todo território". ${ }^{12}$ Nahas em sua revista e em suas poesias mostra-se um patriótico cidadão, assim não poderia de deixar de comentar como muita pompa a indicação dos três republicanos da Ilha para ministros do país. Dessa forma dedica a apoteose final de sua revista aos ministros e ao Estado de Santa Catarina, exaltando-os, ilustrando bem o orgulho da cidade diante esse fato.

\section{O republicano da língua afiada}

Ao ler a revista A Ilha dos Casos Raros, podemos ter uma noção dos valores éticos e morais que nortearam a vida e obra de seu autor. Nahas não se esconde por de trás de sua obra, ao contrário, se expõe politicamente e socialmente, não poupando ironia e deboche as pessoas e atitudes que reprovava, ridicularizando-as em sua revista. Além disso, sua obra tem uma forte carga de denúncia política e social a todos os segmentos da sociedade floriapolitana, fazendo críticas mesmo ao meio do qual ele era integrante.

Sua revista provocou na estréia um mal-estar generalizado na platéia, que a recebeu com um "mudismo" segundos os jornais da época ${ }^{13}$, certamente reconhecendose em seus hábitos e costumes nas criticas e ridicularizações feitas por Nahas, o que não foi digestivo, mas constrangedor. Por essa razão os jornais criticaram o tom pesado e pessoal das cenas, sugerindo a Nahas que alterasse algumas falas e tirasse as referencias pessoais. $\mathrm{O}$ autor para melhor ser recebido pela audiência alterou algumas cenas, o que foi recebido pelos jornais com simpatia, e auxiliou para que a revista fosse recebida de

\footnotetext{
${ }^{12}$ SANCHET, 1998, p.308.

${ }^{13}$ Recortes de jornais do caderno de anotações de Nicolau Nagib Nahas - material cedido para pesquisa por seu filho Gilberto Nahas.
} 
forma mais calorosa pelo público, tornando-se umas das principais produções locais da época.

Nas primeiras cenas, Nahas dá uma prévia ao público, do que virá, através da fala do forasteiro apresenta o pretexto para que se passe a cidade em revista:

FORASTEIRO: desejava que V.S me informasse alguém que me servisse de cicerone e me mostrasse os logares (sic) mais conhecidos e as obras mais importantes desta ilha que se afigura encantadora e adorável. ${ }^{14}$

Nahas não apresenta apenas os lugares belos e as obras de Hercílio Luz, mas também os tipos e situações que eram comuns na cidade dos casos raros, num tom denunciativo e caricato. A revista tem como cenário inicial o Café Java ${ }^{15}$, um lugar de família, freqüentado por mulheres e crianças. O Café recebe enquanto o Forasteiro e o Cicerone ali estão, variados tipos da ilha que são motivos de sátira e principalmente crítica e denúncia de Nahas. $\mathrm{O}$ autor parodia todos os tipos possíveis que habitavam a ilha, desde turcos, portugueses até os conhecidos anedotista e contadores de histórias. Neste cenário Nahas faz sua primeira denúncia, referindo-se aos fiscais de minas, que apenas tiravam vantagem do trabalho de terceiros, na realidade nada fazendo, criticando veementemente suas condutas, como podemos ver no seguinte diálogo:

FARASTEIRO: caçadores...

CICERONE: que pouco vão à caça. Caçam nos cafés, conversando e as vezes chegam até a brigarem. Assim são os nosso fiscaes (sic) de minas.

FORASTEIRO: que recebem os metais e que nunca vão as minas. $^{16}$

Logo em seguida entram os fiscais e num número musicado, cantam:

Se nós não vamos as minas

Fazer fiscalização,

É porque isto não passa

\footnotetext{
${ }^{14}$ NAHAS, 1927, s/p.

${ }^{15} \mathrm{O}$ café Java na realidade chamava-se Café Bruno (um dos patrocinadores da peça) e localizava-se onde até o final da década de 1990 havia o Senadinho, no conhecido Ponto Chic na Rua Felipe Schmith.

${ }^{16}$ NAHAS, 1927, s/p.
} 
De uma grande cavação ${ }^{17}$

Assim, Nahas os ridiculariza mostrando o despreparo e falta de conhecimento sobre metais, não criticando no texto apenas essa classe, mas se referindo a todos os funcionários públicos que tem cargos graças ao prestígio político e não por competência e que exploram os verdadeiros trabalhadores. Assim o forasteiro se encontra com uma das mazelas da cidade, a corrupção. A partir daí, Nahas aponta o caráter de sua revista e sua postura de defesa as classes marginalizadas da Ilha.

Nesta época no país o sistema eleitoral era muito frágil, sendo muito comum fraudes nas eleições, agravando-se pelo fato de o voto não ser secreto, o que gerava muita compra de votos e coerções. Nahas não poupa críticas nem mesmo ao filho de Hercílio Luz, a Abelardo Luz, que na revista é acusado de compra de eleitores. Aqui Nahas mostrava sua autonomia e liberdade política, mesmo sendo aliado do PRC, não fez vista grossa a corrupção interna do partido, não deixando, portanto, de criticar o filho daquele que irá homenagear durante toda a peça. $\mathrm{Na}$ "cena dos eleitores" o autor aproveita para defender e reivindicar o voto secreto no país, no seguinte verso: "se o voto secreto vem, seremos coisa algum dia!", Nahas alude à situação de humilhação e coerção que os eleitores eram obrigados a passar, não tendo direito à soberania e liberdade de escolha.

Além das críticas de caráter político, Nahas também fez críticas sociais e de costumes da sociedade florianopolitana, criticando através de caricaturas pessoais, personalidades da cidade, tais como políticos, falsos intelectuais, bêbados, policiais autoritários, jovens dos clubes sociais da Ilha que Nahas acusava de esnobes e ostentadores, e etc. Nahas desfila no palco os principais acontecimentos de 1926, desde corrupção, fraudes ${ }^{18}$ até a violência na pacata Florianópolis. Mesmo de forma discreta, Nahas aborda o episódio onde jornalistas foram agredidos por policiais munidos de cacetetes, aqui chamado de "pausinho", não poupando critica e ridicularização aos policiais e ao Chefe de polícia no Estado que introduziu o uso desse armamento em Florianópolis. Segundo os jornais da época "o povo compreendeu a alusão aos que

\footnotetext{
${ }^{17}$ NAHAS, 1927, s/p.

${ }^{18}$ Caso da fraude do leite de vaca na cidade, que estava sendo misturado com água pelos agricultores para melhor rendimento. $\mathrm{O}$ caso provocou muita confusão e revolta na cidade.
} 
pretendem calar os jornalistas a porrete e a bala, prorrompeu numa vibrante salva de palmas". ${ }^{19}$

Com todas essas críticas aos costumes e acontecimentos da Ilha, Nahas faz com que sua obra remeta-se ao seu tempo, discuta-o. Sem preocupações históricas por parte do autor, que estava comprometido com a atualidade de sua revista apenas, a revista nos fornece até certa medida um parâmetro de como era vista a cidade por seus próprios cidadãos, além disso, como um integrante da elite cultural da Ilha se relacionava com esses acontecimentos e o debatia através de sua obra. Porém, toda análise é vaga, dedutiva, e muitas vezes arbitrária, produzindo conclusões inclusas e teses contraditórias, devido à análise apenas literária da obra, e não plástica. Não temos condições, por falta de documentação, de saber como a revista foi representada, como os atores deram ênfases aos duplos sentidos, ironias e paródias, não ignorando o fato de que uma obra é uma coisa no papel e outra muito diferente no palco. Portando, a análise da revista $A$ ilha dos casos raros se torna uma interpretação posterior sobre o material literário apenas, cabendo-nos confrontá-lo com a história dessa época, seus acontecimentos e com o próprio autor. Para tentar entender não essa época, mas como ela foi vista e retratada nos palcos de sua cidade, por sua gente, para então compreender o fazer teatral na Ilha e sua importância, mas isso é assunto para um próximo artigo.

\section{Referências Bibliográficas:}

ANTUNES, Delson. Fora do sério: um panorama do Teatro de Revista no Brasil. Rio de Janeiro: FUNARTE, 2002.

COLLAÇO, Vera. Se a moda pega: o teatro de revista em Florianópolis 1920/1930. Florianópolis: Ed. da UDESC, 2007.

\footnotetext{
${ }^{19}$ Recorte colado no programa da peça por Nahas, sem referencias de qual jornal se tratava, apenas informando ser do ano de 1927.
} 
FLORES, Maria Bernadete Ramos; LEHMKUHL, Luciene e COLLAÇO, Vera. A casa do baile - Estética e Modernidade em Santa Catarina. Florianópolis; Fundação Boiteux, 2006.

GOMES, Tiago de Melo. Um espelho no palco - identidades sociais e massificação da cultura no teatro de revista dos anos 1920. Campinas; Editora da Unicamp, 2004.

LENZI, Carlos Alberto Silveira. Partidos e Políticos de Santa Catarina. Florianópolis: Editora da UFSC, 1983.

VENEZIANO, Neyde. Não adianta chorar: teatro de revista brasileiro... Oba!. Campinas: Ed. da UNICAMP, 1996.

O teatro de revista no Brasil: dramaturgia e convenções .

Campinas: Ed. da UNICAMP, 1991.

NAHAS, Nicolau Nagib. Canções Incultas. Florianópolis; Livraria Central, 1922.

A Ilha dos casos raros. (não publicado- material cedido para pesquisa por seu filho Gilberto Nahas)

por seu filho Gilberto Nahas)

Diário Pessoal. (não publicado - material cedido para pesquisa Caderno de anotações. (não publicado - material cedido para pesquisa por seu filho Gilberto Nahas)

. Material de jornal. (não publicado - material cedido para pesquisa por seu filho Gilberto Nahas)

PAIVA, Salvyano Cavalcanti de. Viva o rebolado! - Vida e morte do teatro de revista brasileiro. Rio de Janeiro; Nova Fronteira, 1991.

SACHET, Celestino; SACHET, Sérgio. Santa Catarina: 100 anos de história. Florianópolis: Século Catarinense, 1998. 